\title{
Supporting Information: \\ Butene Oligomerisation by Phosphoric Acid catalysis: Separating the effects of temperature and catalyst hydration on product selectivity
}

\author{
Arno de Klerk *, Dieter O. Leckel and Nicolaas M. Prinsloo \\ Fischer-Tropsch Refinery Catalysis, Sasol Technology Research and Development, \\ P.O. Box 1, Sasolburg 1947, South Africa. \\ Tel: +27 16 960-2549, Fax: +2711 522-3517, E-mail: arno.deklerk@sasol.com
}

\section{Analysis of phosphoric acid species by HPLC-IC}

Background. High performance liquid chromatography, combined with ion-chromatography (HPCL-IC) is a proven method for the analysis of phosphoric acid species. ${ }^{1-5}$ Although the methodology has been describe in broad terms, the general method description often glossed over some important points of detail. It was therefore decided to include details of the analysis method in the paper and include details on the verification of the method as supporting information. Hopefully this will be helpful to those who wish to repeat such work.

Experimental. Details of the analysis method have been included in the paper. It enabled the separation of the oligomeric phosphoric acid species to P14 (Figure S1). The instrument was properly calibrated with pentasodium triphosphate, tetrasodium pyrophosphate decahydrate and orthophosphoric acid. The linearity of conductivity response with increasing concentration was determined for peak area and peak height. Based on these results it was decided to use peak area as quantitative measure, since it had a smaller specie dependent bias than was found with peak height. Injection volume did not have an influence on the response of the phosphoric acid species (Figure S2) and showed no systematic trend with injection volume. The sample standard deviation for all species, except P14, was in the range 2-11\% and showed no systematic trend either. The large variation in values for P14 is a consequence of the small signal-to-noise ratio. 
Phosphoric acid species. The distribution of phosphoric acid species at different phosphoric acid concentrations determined experimentally by HPLC-IC was compared to the values reported in literature. ${ }^{6-8}$

In the range $100-108 \% \mathrm{H}_{3} \mathrm{PO}_{4}$ the values are reasonably close (Figures S3a-S3c). A mass balance over the species found, indicated that the phosphoric acid concentrations of some of the samples that were analysed were slightly different to the values reported: the $100 \% \mathrm{H}_{3} \mathrm{PO}_{4}$ was $102 \%$ and the $108 \% \mathrm{H}_{3} \mathrm{PO}_{4}$ was $107 \%$.

The more concentrated phosphoric acid samples deviated much more from the literature values (Figures S3d-S3e). The mass balance again indicated that the phosphoric acid concentrations that were analysed were different to the value reported: the $115 \% \mathrm{H}_{3} \mathrm{PO}_{4}$ was $114 \%$ and the $117 \% \mathrm{H}_{3} \mathrm{PO}_{4}$ was $115.5 \%$. From the work of Jameson ${ }^{6}$ it is known that higher condensed species and metaphosphoric acid species may be present and a bias towards lighter phosphoric acid species could have skewed the HPLC-IC analysis. Nevertheless, a Flory-plot ${ }^{9}$ of the data (Figure S4) showed that the data sets were all internally consistent, with only the P1 specie being lower than expected in all instances. It was also clear that the present HPLC-IC method could not determine P14 accurately, which was suspected from the small signal-to-noise ratio mentioned previously.

Hydrolysis rate. The stability of the phosphoric acid species by mixing it with $\mathrm{LiOH}$ was evaluated. It was found that at $80^{\circ} \mathrm{C}$ hydrolysis sodium triphosphate in deionised water occurred at a steady rate and the composition changed meaningfully in a matter of hours (Figure S5). In comparison the solution of $104 \% \mathrm{H}_{3} \mathrm{PO}_{4}$ stabilised with $\mathrm{LiOH}$ at a $\mathrm{pH}$ of 9 , was stable at $80^{\circ} \mathrm{C}$, with very little hydrolysis being observed over a period of days (see Figure 1 in accompanying paper).

The effect of temperature on the hydrolysis rate of unstabilised solutions of $115 \%$ $\mathrm{H}_{3} \mathrm{PO}_{4}$ was studied. This showed that hydrolysis was measurable but slow at $25^{\circ} \mathrm{C}$ (Figure S6a), with little change being seen on the time scale of 1 hour. The preferred hydrolysis product was $\mathrm{P} 3$, with the increase in $\mathrm{P} 1$ and $\mathrm{P} 2$ being much slower. At $60^{\circ} \mathrm{C}$ the hydrolysis rate was much faster (Figure S6b). Again P3 was the preferred hydrolysis product and the P3 concentration rose by more than $30 \%$ within the first hour. The same was seen at $80^{\circ} \mathrm{C}$, confirming that P3 is preferentially formed during hydrolysis and is itself hydrolysed at a much slower. By using a methodology similar to that of Abbott, ${ }^{10}$ rate constants were calculated for the hydrolysis of the various phosphoric acid species (Table S1). It should be 
noted that these values are suitable for qualitative predictions only, since the experiments were not designed to obtain kinetic data.

\section{Spectroscopic analysis of butene oligomerisation products}

Background. Gas chromatography with flame ionisation detection (GC-FID) was used as primary method for the characterisation of the butene oligomerisation products. GC-FID is a quite powerful analytical technique, but perfect separation of complex mixtures is not always possible. Furthermore, identification of the compounds presents a problem due to the abundance of isomers, lack of standards and inability of mass spectrometry to clearly differentiate between isomers. Although spectroscopic techniques are not able to resolve this shortcoming, they are able to quantify specific structural attributes in the mixture. Such techniques can also be used in combination with chemometrics to cross-check the GC-FID data and thereby improve data confidence.

Experimental. Details of the GC-FID analysis method have been included in the paper. Some samples were also analysed by gas chromatography with chemical ionisation mass spectrometry (GC-CI-MS) to check the carbon number distribution. The instrument used was an Agilent 6890N with Agilent 5973 mass selective detector and chemical ionisation attachment, using methylpropane as ionisation agent. The spectroscopic methods used were IR, NIR and ${ }^{1} \mathrm{H}$ NMR. Phosphorus incorporation in the product was determined by ICPAES. The experimental conditions used for each butene oligomerisation run are listed in Table S2.

IR spectra were collected on an ABB Bomem "Arid-Zone" Fourier-transform infrared

spectrometer at a resolution of $4 \mathrm{~cm}^{-1}$ and spectra were averaged over 30 scans in the spectral range $400-4000 \mathrm{~cm}^{-1}$. The samples were conditioned at $10^{\circ} \mathrm{C}$ in a Harrick temperature controlled variable path length flow cell with zinc selenide windows. The path length was $0.025 \mathrm{~mm}$ and the cell was wedged with a $0.012 \mathrm{~mm}$ spacer on the one side to eliminate spectral interference fringes.

NIR spectra were collected on a laboratory model NIRSystems 6500 spectrometer at a resolution of $1 \mathrm{~nm}$ and spectra were averaged over 32 scans in the spectral range 1300-2130 $\mathrm{nm}$. The samples were conditioned for 1 hour in a circulating cooling bath (Lauda ecoline RE120) set at $10^{\circ} \mathrm{C}$. Air was used at background and a fibre optic transflectance probe with 3 $\mathrm{mm}$ gap (6 $\mathrm{mm}$ path length) were used for sample acquisition. 
The ${ }^{1} \mathrm{H}$ NMR spectra were collected on a Varian Mercury $400 \mathrm{MHz}$ NMR. A large spectral window ( $9.2 \mathrm{kHz}$ which corresponds to a window of 15 to $-8 \mathrm{ppm})$, long relaxation time and small pulse angle $\left(33^{\circ}\right)$ was used with an internal standard to obtain quantitative data. The internal standard used was 1,4-dioxane (Aldrich, 99\%) that has one NMR resonance with a chemical shift of $3.53 \mathrm{ppm}$, which does not overlap with any analyte peaks. All samples were dissolved in deuterated chloroform.

Phosphorus content was determined by ICP-AES in organic mode on a Perkin Elmer Optima DV instrument. A power setting of $1.45 \mathrm{~kW}$ was used and quantification was done using the phosphorus emission at $213.6 \mathrm{~nm}$.

Carbon number distribution. A convenient way of estimating the carbon number distribution of an oligomerisation product, is to use the $n$-paraffins as marker compounds and consider all peaks that elute between two $n$-paraffins on a boiling point separating column as belonging to a specific carbon number. For example, in Figure S7 the peaks eluting between $n$-hexane and $n$-heptane is considered $\mathrm{C}_{7}$ hydrocarbons. Although this works well for hydrocarbons in the $\mathrm{C}_{7}$ and lighter range, some of the branched olefins of $\mathrm{C}_{8}$ and heavier compounds have boiling points less than that of $n$-octane. In practice there is much overlap of $\mathrm{C}_{8}$ and heavier olefins. This can be seen from the bracketing of carbon numbers (Figure S7) based on best correlation with the true carbon number distribution determined by GC-ICMS. The bracketing indicated is sample specific and reflects the nature of the process from which it was derived. It is clear that reporting a carbon number distribution based on GCFID results is fraught with error unless GC-CI-MS is used to positively identify the molecular ion and correctly assigning individual peaks.

Phosphorus incorporation. The results of the phosphorus analyses (Table S3) showed that little or no phosphorus incorporation took place. This was expected, since only ethene and propene are known to form stable phosphoric acid esters. ${ }^{11}$ It also confirmed that proper phase separation between the organic phase and LPA was achieved.

Olefin distribution. The distribution of olefin types has been determined by IR (Table S4) and ${ }^{1} \mathrm{H}$ NMR (Table S5). This data will be discussed with a much larger data set collected during butene oligomerisation over solid phosphoric acid (SPA). ${ }^{12}$ 


\section{Analysis of aromatics in the oligomerisation product}

Background. The aromatics content in the oligomerisation product was used as an indirect measure of the catalyst deactivation propensity at different temperature and phosphoric acid concentrations.

Experimental. Details of the HPLC-RI analysis method has been included in the paper. In addition to that, the aromatics content of the liquid product was also determined by a photodiode array ultra-violet detector (Waters 2996) at wavelengths of $324 \mathrm{~nm}$ and $254 \mathrm{~nm}$. The response of the various aromatic groups is different, requiring calibration with reference compounds for quantitative analysis. This was not done and the HPLC-UV data is therefore qualitative only and was merely used to increase confidence in the HPLC-RI analyses.

Aromatics distribution. The distribution of mono-, bi- and polycyclic aromatics can be deduced from the retention times of the different classes (Figures S8a and S8b). No further work was done to positively identify the compounds and based on the retention times, it was concluded that little, if any, polycondensed material formed.

\section{Acknowledgement}

The contribution of one of the authors (DOL) to the development and verification of the HPLC methods is much appreciated and similarly another of the authors (NMP) for the spectroscopic work. All work was done at Sasol Technology Research and Development and permission to publish the results is appreciated.

\section{Literature cited}

(1) Shintani, H.; Dasgupta, P. K. Gradient anion chromatography with hydroxide and carbonate eluents using simultaneous conductivity and pH detection. Anal. Chem. 1987, $59,802$.

(2) Stover, F. S.; Bulmahn, J. A.; Gard, J. K. Polyphosphate separations and chain length characterization using minibore ion chromatography with conductivity detection. $J$. Chromatogr. A 1994, 688, 89. 
(3) Baluyot, E. S.; Hartford, C. G. Comparison of polyphosphate analysis by ion chromatography and by modified end-group titration. J. Chromatogr. A 1996, 739, 217.

(4) Svoboda, L.; Schmidt, U. Single-column ion chromatography of linear polyphosphates. J. Chromatogr. A 1997, 767, 107.

(5) Sekiguchi, Y.; Matsunaga, A.; Yamamoto, A.; Inoue, Y. Analysis of condensed phosphates in food products by ion chromatography with an on-line hydroxide eluent generator. J. Chromatogr. A 2000, 881, 639.

(6) Jameson, R. F. The composition of the "strong" phosphoric acids. J. Chem. Soc. 1959, 752.

(7) Huthi, A-L.; Gartaganis, P. A. The composition of the strong phosphoric acids. Can. J. Chem. 1956, 34, 785 .

(8) Ohashi, S.; Sugatani, H. The composition of strong phosphoric acids. Bull. Chem. Soc. Japan 1957, 30, 864.

(9) Flory, P. J. Random reorganization of molecular weight distribution in linear condensation polymers. J. Am. Chem. Soc. 1942, 64, 2205.

(10) Abbot, G. A. The rate of hydration of pyrophosphoric acid in aqueous solution. J. Am. Chem. Soc. 1909, 31, 763.

(11) Ipatieff, V. N. Catalytic polymerization of gaseous olefins by liquid phosphoric acid. I. Propylene. Ind. Eng. Chem. 1935, 27, 1067.

(12) De Klerk, A.; Leckel, D. O.; Mashapa, T.; Prinsloo, N. M.; Strauss, M. J. Butene Oligomerisation by Phosphoric Acid catalysis: Effect of kieselguhr on product properties. Ind. Eng. Chem. Res. (to be submitted for publication). 
Table S1. Approximate hydrolysis rate constants $\left(\mathrm{h}^{-1}\right)$ calculated for the hydrolysis of P5-P14 phosphoric acid species at 25,60 and $80^{\circ} \mathrm{C}$ in deionised water without $\mathrm{pH}$ adjustment after 1 hour of contact time. (These are effective overall rates and both formation and depletion reactions are incorporated).

\begin{tabular}{cccc}
\hline $\begin{array}{c}\text { Phosphoric } \\
\text { acid specie }\end{array}$ & 25 & 60 & 80 \\
\hline P5 & 0.04 & 0.20 & 1.4 \\
P6 & & 0.31 & 3.1 \\
P7 & 0.03 & 0.37 & 8.2 \\
P8 & 0.05 & 0.66 & \\
P9 & 0.04 & 1.5 & \\
P10 & 0.11 & 3.1 & \\
P11 & 0.14 & 4.6 & \\
P12 & 0.14 & & \\
P13 & 0.15 & & \\
P14 & 0.25 & &
\end{tabular}


Table S2. Experimental conditions and olefin conversion during butene oligomerisation test runs with LPA.

\begin{tabular}{|c|c|c|c|c|c|c|}
\hline Run & & $\begin{array}{c}\text { Temperature } \\
\left({ }^{\circ} \mathrm{C}\right)\end{array}$ & $\begin{array}{c}\mathrm{H}_{3} \mathrm{PO}_{4} \\
(\%)\end{array}$ & $\begin{array}{c}\mathrm{H}_{3} \mathrm{PO}_{4} \\
(\mathrm{~g})\end{array}$ & $\begin{array}{c}\text { Butene feed } \\
\text { (g) }\end{array}$ & $\begin{array}{c}\text { Conversion } \\
(\%)\end{array}$ \\
\hline Blank & $\dagger$ & - & - & - & - & - \\
\hline 2 & $\ddagger$ & 150 & 100 & 190 & 294 & 16 \\
\hline 3 & & 150 & 100 & 380 & 298 & 22 \\
\hline 4 & & 250 & 115 & 400 & 262 & 18 \\
\hline 5 & & 250 & 100 & 360 & 254 & 26 \\
\hline 6 & & 150 & 115 & 402 & 265 & 35 \\
\hline 7 & & 200 & 100 & 359 & 270 & 15 \\
\hline 8 & & 200 & 108 & 420 & 273 & 20 \\
\hline 9 & & 200 & 115 & 430 & 264 & 23 \\
\hline 10 & & 150 & 108 & 399 & 250 & 40 \\
\hline 11 & & 250 & 108 & 397 & 272 & 25 \\
\hline
\end{tabular}


Table S3. Phosphorus content as determined by ICP-AES with P emission at $213.6 \mathrm{~nm}$.

\begin{tabular}{cc}
\hline Run & $\mathrm{P}\left(\mu \mathrm{g} \cdot \mathrm{g}^{-1}\right)$ \\
\hline Blank & $<1$ \\
2 & $<1$ \\
3 & 1 \\
4 & $<1$ \\
5 & $<1$ \\
6 & $<1$ \\
7 & 1 \\
8 & $<1$ \\
9 & $<1$ \\
10 & $<1$ \\
11 & 2
\end{tabular}


Table S4. Infrared absorbance integrals for different structural types in the LPA olefin oligomerisation product.

\begin{tabular}{|c|c|c|c|c|c|c|c|}
\hline \multirow[t]{2}{*}{ Run } & \multirow{2}{*}{$\begin{array}{c}\mathrm{CH}_{2}=\mathrm{CHR} \\
909 \mathrm{~cm}^{-1}\end{array}$} & \multirow{2}{*}{$\begin{array}{c}\mathrm{CH}_{2}=\mathrm{CR}_{2} \\
892 \mathrm{~cm}^{-1}\end{array}$} & cis $\mathrm{RHC}=\mathrm{CHR}$ & trans $\mathrm{RHC}=\mathrm{CHR}$ & \multirow{2}{*}{$\begin{array}{c}\mathrm{RHC}=\mathrm{CR}_{2} \\
820 \mathrm{~cm}^{-1}\end{array}$} & \multirow{2}{*}{$\begin{array}{c}\mathrm{RHC}=\mathrm{CR}_{2} \\
1670 \mathrm{~cm}^{-1}\end{array}$} & \multirow{2}{*}{$\begin{array}{c}-\mathrm{CH}_{2}-\mathrm{CH}_{2}- \\
740 \mathrm{~cm}^{-1}\end{array}$} \\
\hline & & & $680 \mathrm{~cm}^{-1}$ & $969 \mathrm{~cm}^{-1}$ & & & \\
\hline 2 & 0.217 & 2.014 & 0.122 & 0.532 & 0.602 & 0.046 & 0.056 \\
\hline 3 & 0.223 & 2.043 & 0.130 & 0.570 & 0.573 & 0.053 & 0.054 \\
\hline 4 & 0.203 & 1.046 & 0.070 & 0.679 & 0.237 & 0.628 & 0.109 \\
\hline 5 & 0.176 & 1.361 & 0.055 & 0.652 & 0.270 & 0.618 & 0.100 \\
\hline 6 & 0.135 & 1.349 & 0.084 & 0.543 & 0.357 & 0.256 & 0.080 \\
\hline 7 & 0.188 & 1.667 & 0.066 & 0.523 & 0.344 & 0.333 & 0.080 \\
\hline 8 & 0.165 & 1.494 & 0.063 & 0.516 & 0.305 & 0.351 & 0.081 \\
\hline 9 & 0.199 & 1.339 & 0.089 & 0.635 & 0.299 & 0.396 & 0.091 \\
\hline 10 & 0.131 & 1.523 & 0.086 & 0.549 & 0.467 & 0.256 & 0.061 \\
\hline 11 & 0.146 & 1.118 & 0.070 & 0.647 & 0.263 & 0.587 & 0.107 \\
\hline
\end{tabular}


Table S5. Normalised ${ }^{1} \mathrm{H}$ NMR integrals for olefin types found in the LPA olefin oligomerisation product.

\begin{tabular}{cccccc}
\hline Run & $\mathrm{CH}_{2}=\mathrm{CHR}$ & $\mathrm{CH}_{2}=\mathrm{CR}_{2}$ & $\mathrm{RHC}=\mathrm{CHR}$ & $\mathrm{RHC}=\mathrm{CR}_{2}$ & $\mathrm{R}_{2} \mathrm{C}=\mathrm{CR}_{2}$ \\
\hline 2 & 0.042 & 0.238 & 0.060 & 0.325 & 0.335 \\
3 & 0.046 & 0.238 & 0.066 & 0.327 & 0.323 \\
4 & 0.027 & 0.168 & 0.067 & 0.354 & 0.384 \\
5 & 0.032 & 0.198 & 0.068 & 0.381 & 0.322 \\
6 & 0.040 & 0.206 & 0.067 & 0.370 & 0.317 \\
7 & 0.034 & 0.224 & 0.056 & 0.356 & 0.330 \\
8 & 0.021 & 0.215 & 0.050 & 0.349 & 0.365 \\
9 & 0.033 & 0.204 & 0.067 & 0.356 & 0.340 \\
10 & 0.022 & 0.200 & 0.055 & 0.351 & 0.372 \\
11 & 0.032 & 0.171 & 0.069 & 0.368 & 0.360
\end{tabular}


Figure S1. Linear gradient elution of $117 \% \mathrm{H}_{3} \mathrm{PO}_{4}$ (stabilised at $\mathrm{pH}=9.5$ ) using $\mathrm{LiOH}$ kept constant for $2 \mathrm{~min}$ at $12 \mathrm{mmol} \cdot \mathrm{l}^{-1}$, then increased to $36 \mathrm{mmol} \cdot \mathrm{l}^{-1}$ over $13 \mathrm{~min}$ and afterwards kept constant for a further $5 \mathrm{~min}$, with the mobile phase flow rate kept constant at 0.75 ml.min ${ }^{-1}$ all the time.

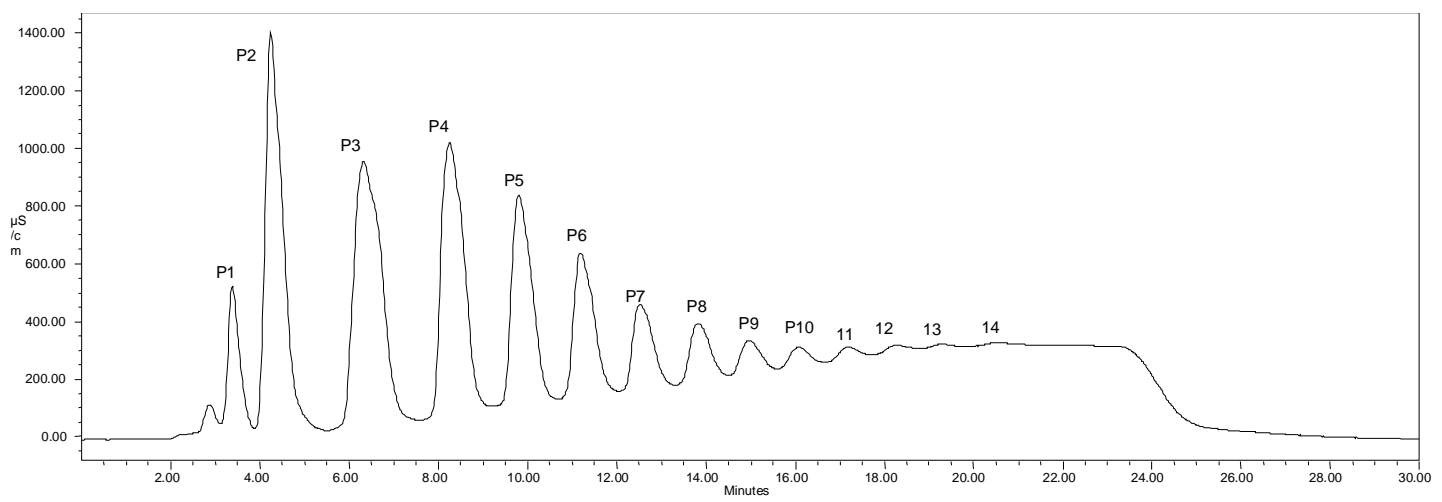


Figure S2. Influence of injection volume on the detector response during HPLC-IC analysis of a $117 \% \mathrm{H}_{3} \mathrm{PO}_{4}$ sample.

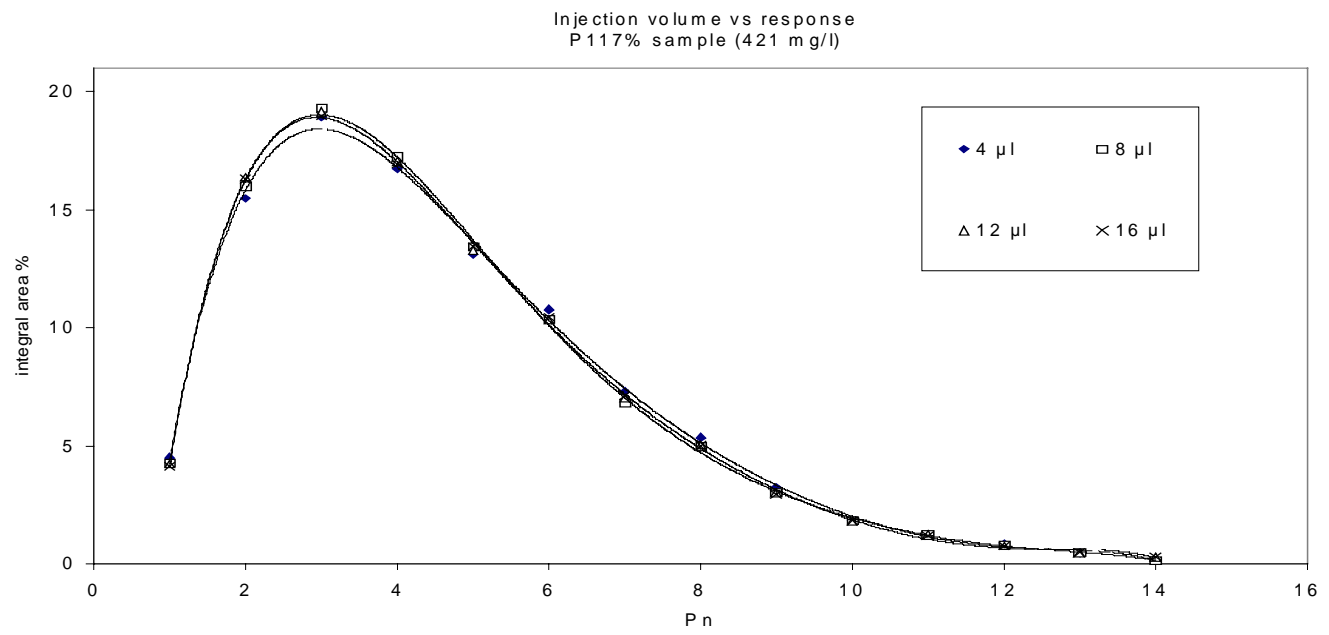


Figure S3a. Distribution of phosphoric acid species obtained by analysis of $100 \% \mathrm{H}_{3} \mathrm{PO}_{4}$ with HPLC-IC ( $)$ and that reported in literature by Jameson ${ }^{6}$ for $101.4 \% \mathrm{H}_{3} \mathrm{PO}_{4}(\mathrm{O})$ and Huthi and Gartaganis ${ }^{7}$ for $101.3 \% \mathrm{H}_{3} \mathrm{PO}_{4}(\Delta)$.

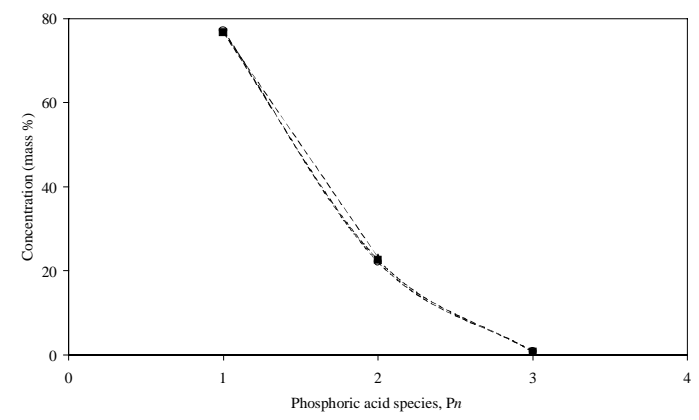

Figure S3b. Distribution of phosphoric acid species obtained by analysis of $104 \% \mathrm{H}_{3} \mathrm{PO}_{4}$ with HPLC-IC ( $\square$ ) and that reported in literature by Jameson ${ }^{6}$ for $104.5 \% \mathrm{H}_{3} \mathrm{PO}_{4}(\circ)$, Huthi and Gartaganis ${ }^{7}$ for $103.7 \% \mathrm{H}_{3} \mathrm{PO}_{4}(\Delta)$ and by Ohashi and Sugatani ${ }^{8}$ for $103.6 \% \mathrm{H}_{3} \mathrm{PO}_{4}(\diamond)$ and $105.2 \% \mathrm{H}_{3} \mathrm{PO}_{4}(\square)$.

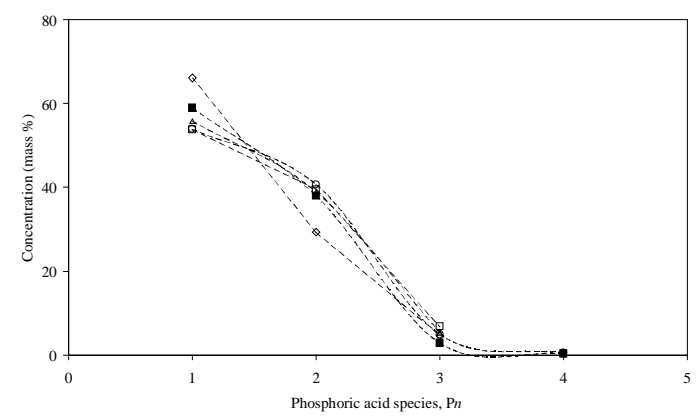

Figure S3c. Distribution of phosphoric acid species obtained by analysis of $108 \% \mathrm{H}_{3} \mathrm{PO}_{4}$ with HPLC-IC ( $\square$ ) and that reported in literature by Jameson ${ }^{6}$ for $107 \% \mathrm{H}_{3} \mathrm{PO}_{4}(\circ)$, Huthi and Gartaganis ${ }^{7}$ for $107.7 \% \mathrm{H}_{3} \mathrm{PO}_{4}(\Delta)$ and by Ohashi and Sugatani ${ }^{8}$ for $108 \% \mathrm{H}_{3} \mathrm{PO}_{4}(\diamond)$.

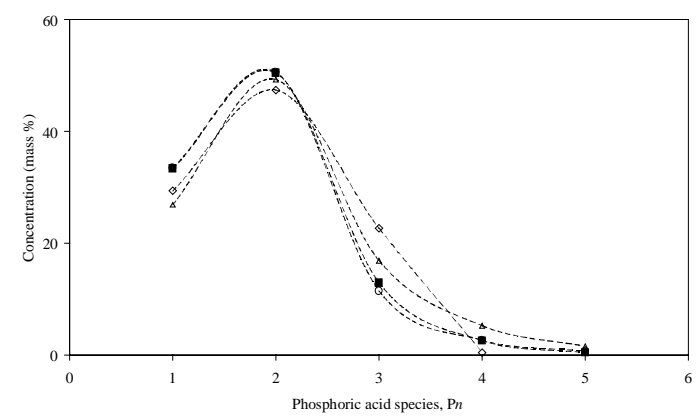


Figure S3d. Distribution of phosphoric acid species obtained by analysis of $115 \% \mathrm{H}_{3} \mathrm{PO}_{4}$ with HPLC-IC ( $)$ and that reported in literature by Jameson ${ }^{6}$ for $116 \% \mathrm{H}_{3} \mathrm{PO}_{4}(\circ)$ and Huthi and Gartaganis ${ }^{7}$ for $115.2 \% \mathrm{H}_{3} \mathrm{PO}_{4}(\Delta)$.

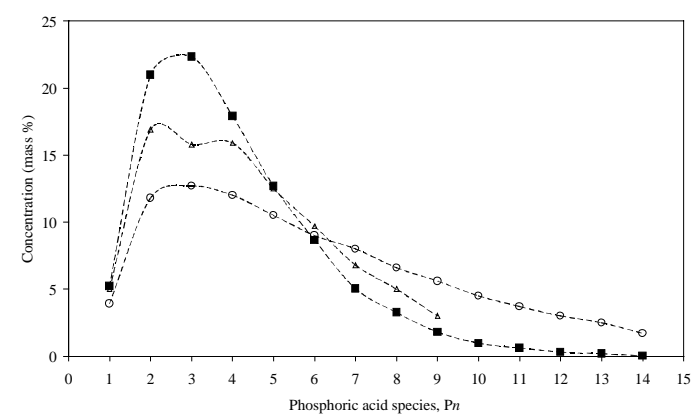

Figure S3e. Distribution of phosphoric acid species obtained by analysis of $117 \% \mathrm{H}_{3} \mathrm{PO}_{4}$ with HPLC-IC ( $\mathbf{a})$ and that reported in literature by Jameson ${ }^{6}$ for $117.3 \% \mathrm{H}_{3} \mathrm{PO}_{4}(\mathrm{O})$ and Huthi and Gartaganis ${ }^{7}$ for $117.2 \% \mathrm{H}_{3} \mathrm{PO}_{4}(\Delta)$.

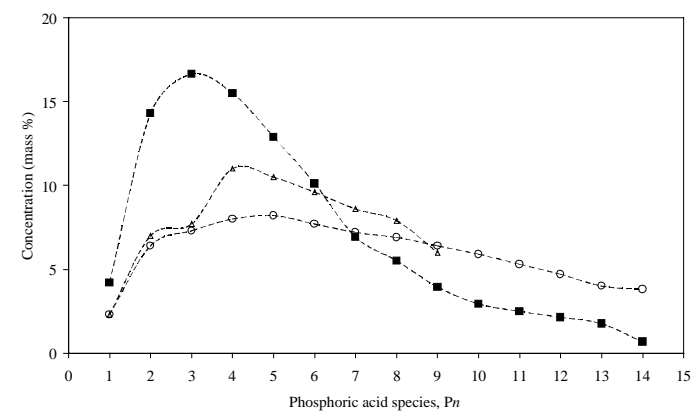


Figure S4. Flory-plot of the data in Figure 3d; $115 \% \mathrm{H}_{3} \mathrm{PO}_{4}$ analysed with HPLC-IC ( $\left.\mathbf{\square}\right)$ and data reported in literature by Jameson ${ }^{6}$ for $116 \% \mathrm{H}_{3} \mathrm{PO}_{4}(\mathrm{O})$ and Huthi and Gartaganis ${ }^{7}$ for $115.2 \% \mathrm{H}_{3} \mathrm{PO}_{4}(\Delta)$.

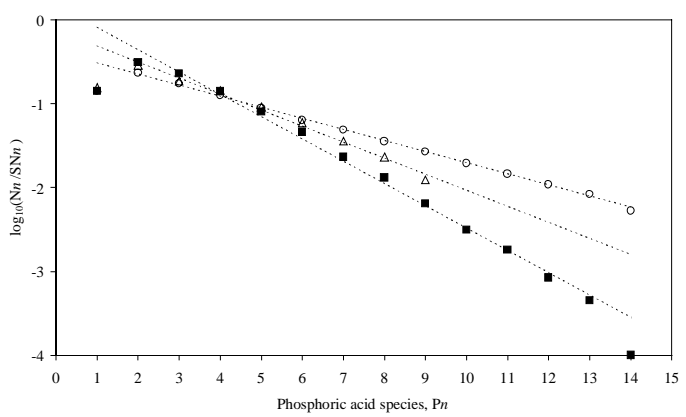


Figure S5. Hydrolysis of a $260 \mu \mathrm{g} \cdot \mathrm{g}^{-1}$ pentasodium triphosphate (Aldrich, 98\%) in deionised water at $80^{\circ} \mathrm{C}$.

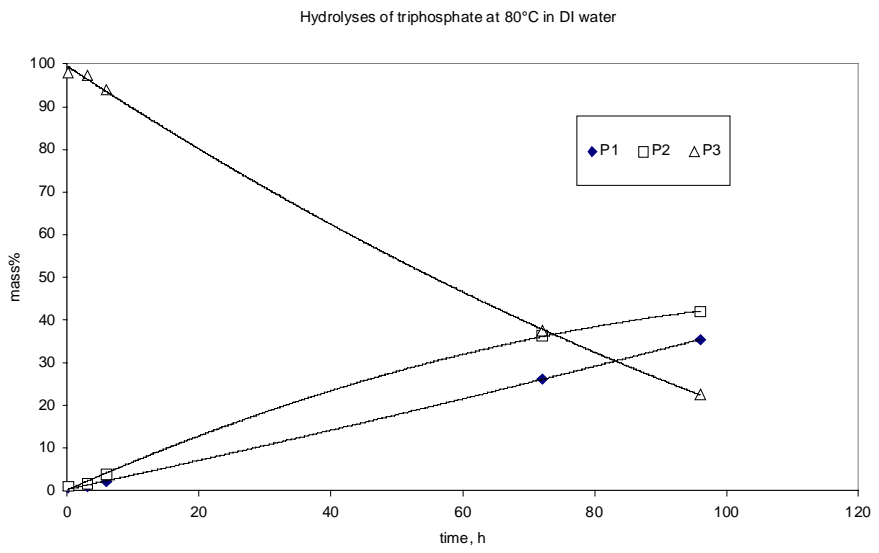


Figure S6a. Hydrolysis at $25^{\circ} \mathrm{C}$ of a dilute solution of $115 \% \mathrm{H}_{3} \mathrm{PO}_{4}$ (Chemifos) in deionised water without $\mathrm{pH}$ adjustment.

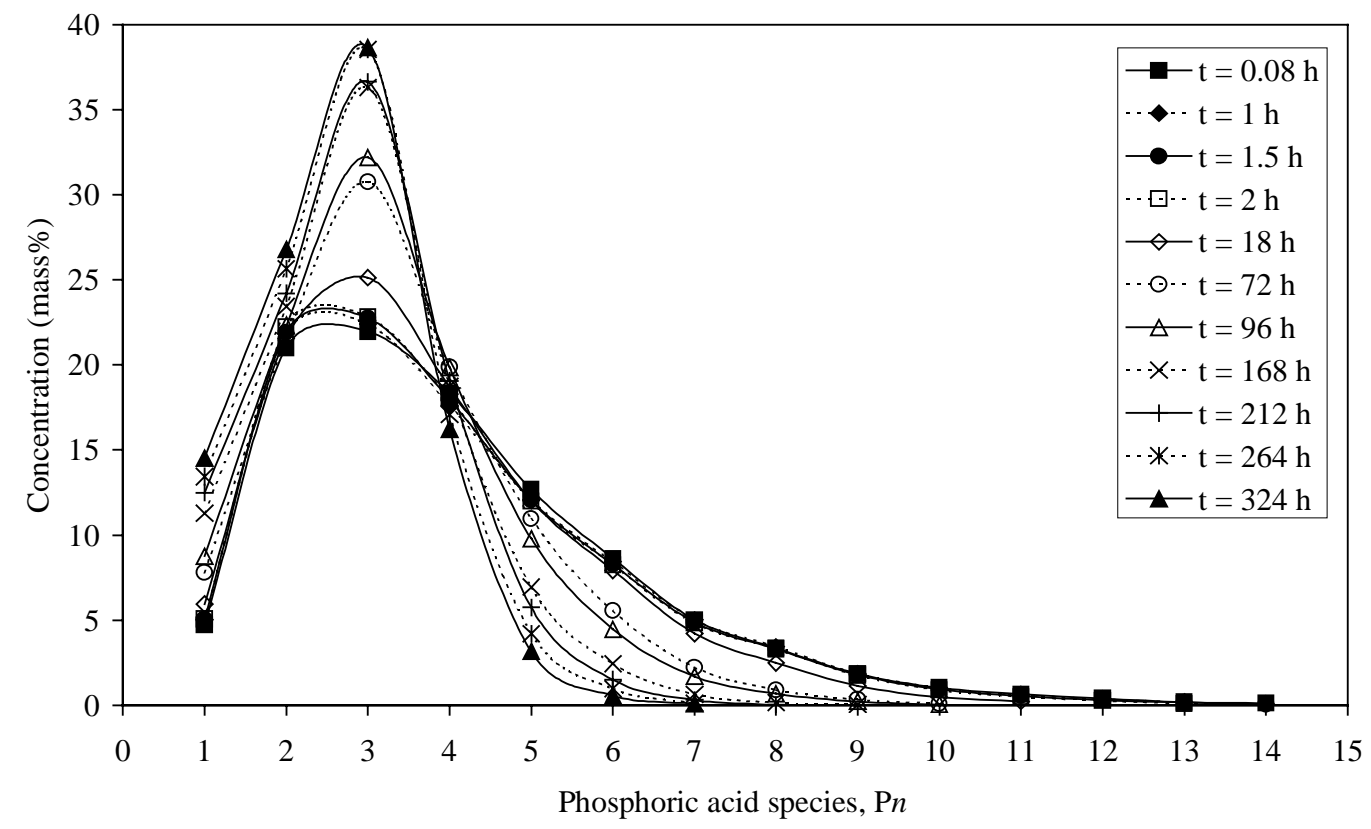

Figure S6b. Hydrolysis at $60^{\circ} \mathrm{C}$ of a dilute solution of $115 \% \mathrm{H}_{3} \mathrm{PO}_{4}$ (Chemifos) in deionised water without $\mathrm{pH}$ adjustment.

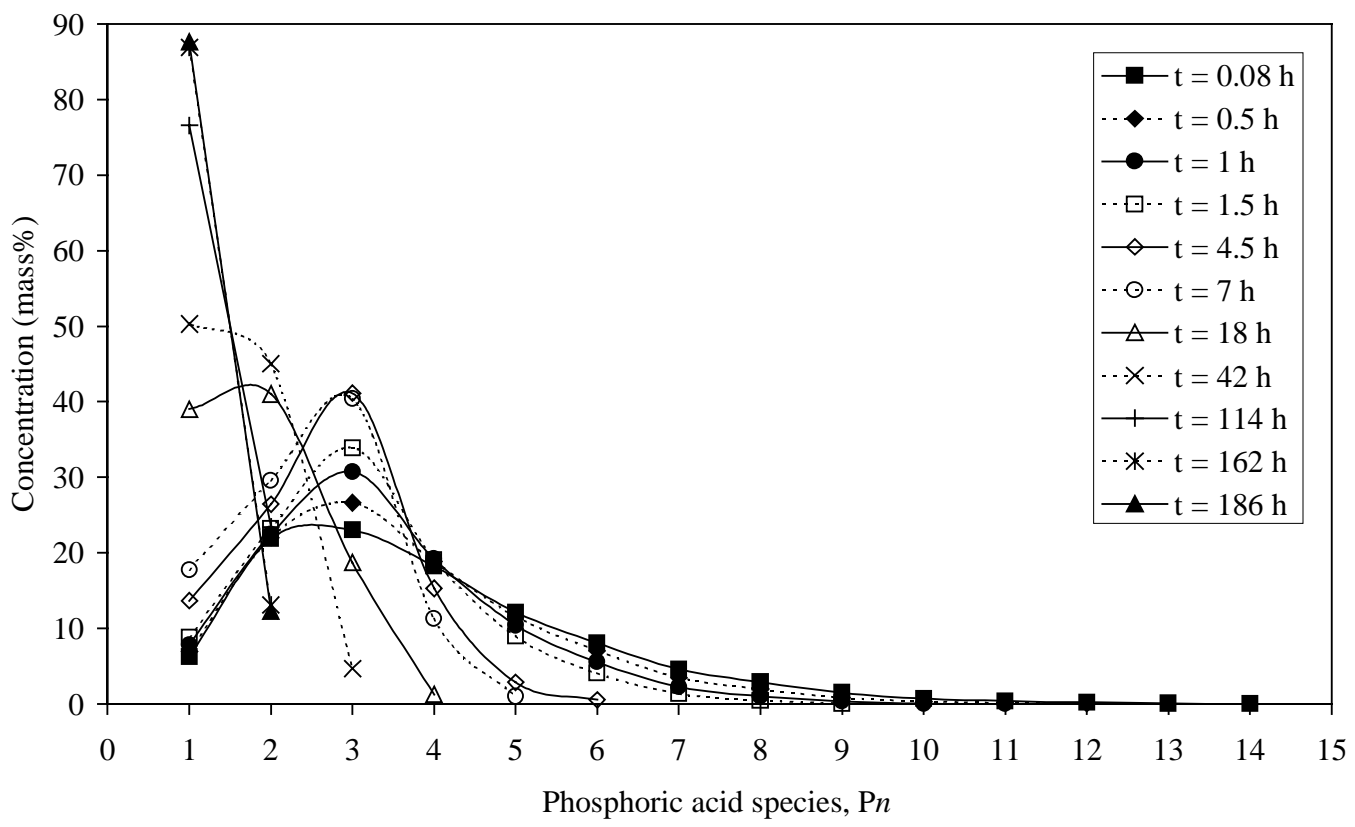


Figure S7. GC-FID chromatogram of an n-paraffin standard overlaid with the GC-FID chromatogram of a typical unhydrogenated butene oligomerisation product from reaction over phosphoric acid.

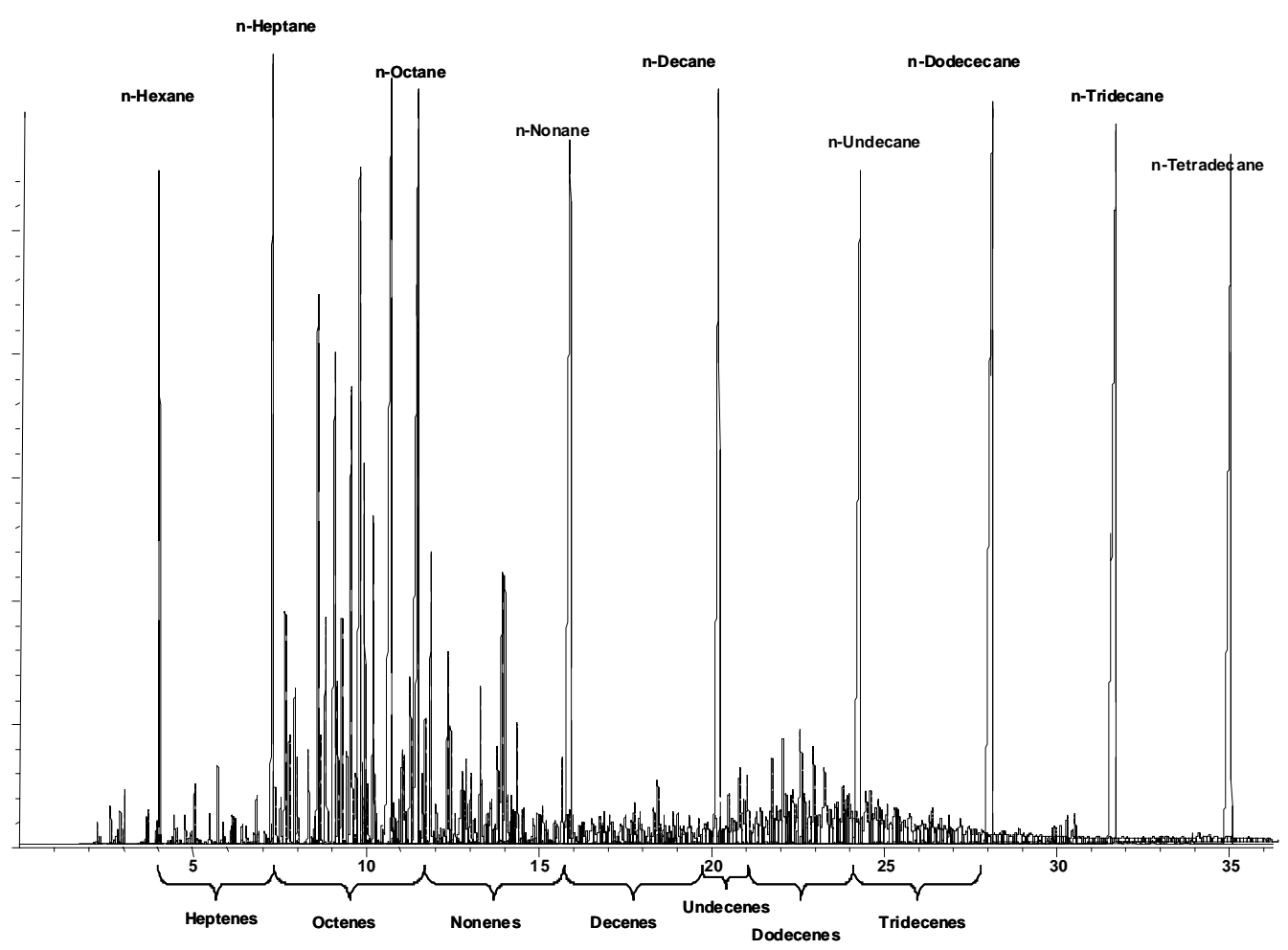


Figure S8a. HPLC-RI chromatogram indicating the aromatics distribution in the liquid product from butene oligomerisation after 4 hours at $250{ }^{\circ} \mathrm{C}$ in contact with $115 \% \mathrm{H}_{3} \mathrm{PO}_{4}$.

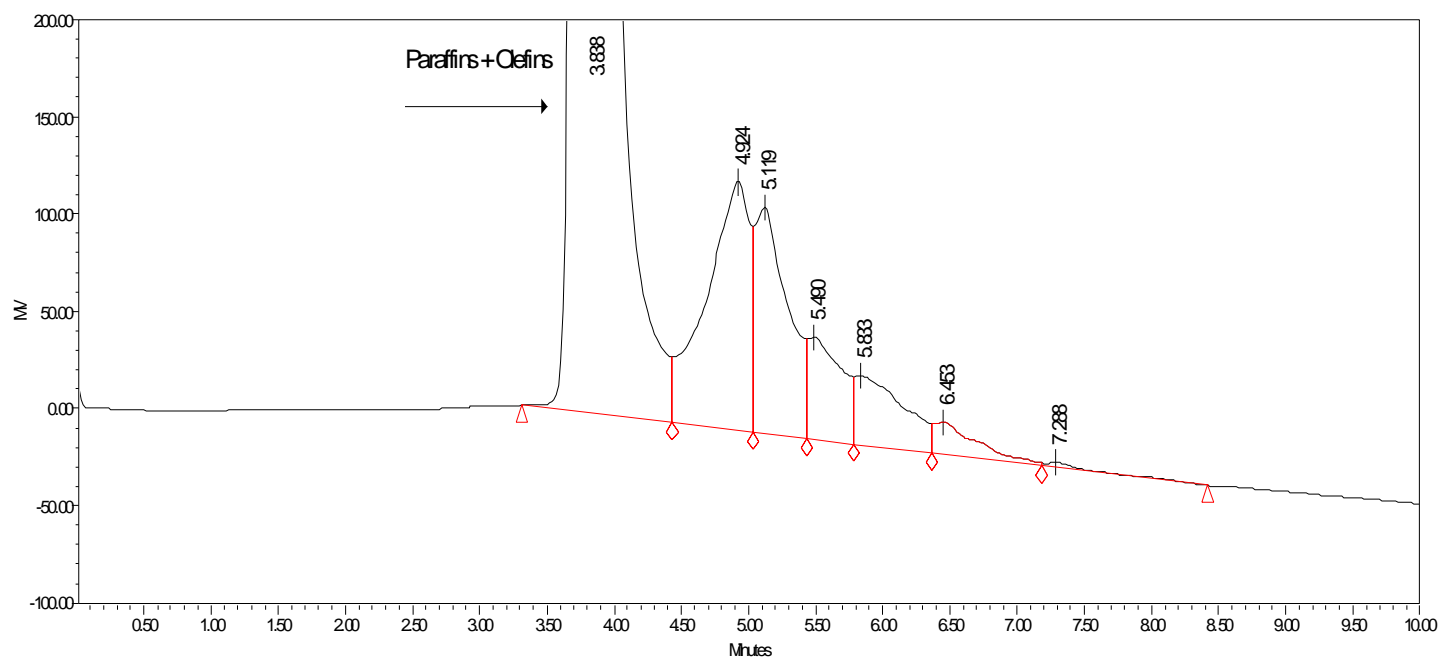

Figure S8b. HPLC-UV chromatogram indicating the aromatics distribution in the liquid product from butene oligomerisation after 4 hours at $250^{\circ} \mathrm{C}$ in contact with $115 \% \mathrm{H}_{3} \mathrm{PO}_{4}$.

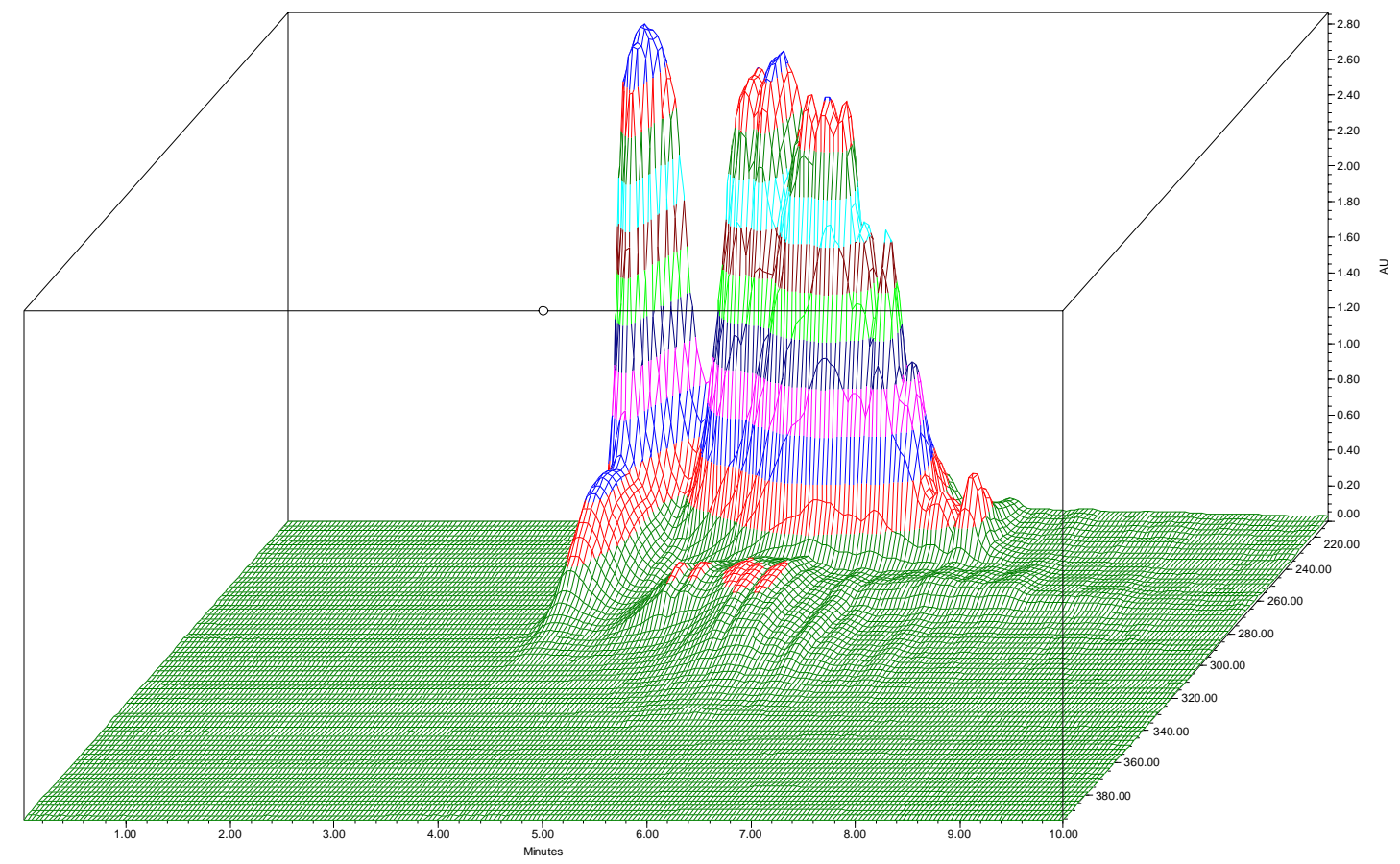

